\title{
"Para quem serve esse diagnóstico?": uma interlocução entre o Psicodiagnóstico e a Psicanálise
}

\author{
"Who is this diagnosis for?":a dialog between Psychodiagnosis and Psychoanalisis \\ Crislayne Flores Oliveira, Fernanda Cabral Samico
}

Como citar esse artigo. Oliveira, C.F.; Samico, F.C. "Para quem serve esse diagnóstico?": uma interlocução entre o Psicodiagnóstico e a Psicanálise. Revista Mosaico - 2019 Jul./Dez.; 10 (2): SUPLEMENTO 105-110

\begin{abstract}
Resumo
A psicanálise, atualmente, encontra um lugar profícuo no campo universitário, notadamente nos cursos de graduação de psicologia. Dessa maneira, o presente artigo é efeito de algumas inquietações advindas de dois campos de saber: o psicodiagnóstico e a psicanálise. Pretendemos dar partida à ação de se interrogar quais os benefícios do diagnóstico para aquele que o requer.Em uma atualidade em que a patologização dos indivíduos se tornou banalizada, a procura por diagnósticos é bastante comum e cabe problematizarmos a nomeação dos sofrimentos em parâmetros de normalidade e doença. Pretendemos, em última análise, sustentar a argumentação de que o aluno de psicologia, ao entrar em contato com a noção de diagnóstico em psicanálise e sua ética, pode ter ferramentas cruciais para problematizar de forma positiva seu trabalho de psicodiagnóstico e adquirir uma postura que o salvaguarde de um mau uso de tal instrumento.

Palavras-chave: Psicodiagnóstico, Psicanálise, Patologização, Normalidade
\end{abstract} (1997) ensina que, contra o saber deserto de desejo que encontramos no teorema lacaniano do discurso da universidade, a psicanálise, quando introduzida em uma instituição de ensino superior, deve alcançar o caminho do discurso do analista e colaborar para o estímulo do desejo de saber. Deste modo, a conexão entre a psicanálise e a academia, se dirigida por psicanalistas, pode ensinar acerca das manifestações particulares de nosso tempo e comportar pensar táticas para garantir que a psicanálise tenha seu campo revigorado por depositar em cena o tempo todo o saber e sua pertinência com a verdade.

Essa conexão reverbera nos psicanalistas que estão inseridos nas universidades uma chamada a se pensar a especificidade da psicanálise enquanto saber e de sua clínica psicanalítica, uma vez que corre o risco de se ver diluída entre as chamadas técnicas e práticas psicológicas. Dessa maneira, o presente artigo é efeito de algumas inquietações advindas de dois campos de saber: o psicodiagnóstico e a psicanálise. A primeira inquietação que se impõe é de que maneira o diagnóstico é estabelecido em ambos os campos; para se decantar em uma segunda interrogação: o que é possível problematizar a partir do viés da psicanálise no fazer do psicodiagnóstico?

Para fins de esclarecimento, é preciso explicar o caminho que levou a escrita deste artigo. Nossa 
experiência em dois estágios - Psicodiagnóstico e Psicanálise com adultos - colocou-nos a relativizar o papel do psicodiagnóstico em nossa contemporaneidade, porque percebemos que o mesmo corre grande risco de se manter sob forte influência do saber biomédico, fazendo-nos pensar: "para quem serve esse diagnóstico?" Essa pergunta demanda uma tomada ética do profissional, e a ação de se interrogar quais são os benefícios do diagnóstico para aquele que o requer. Em uma atualidade em que a patologização dos indivíduos se tornou banalizada, a procura por diagnósticos é bastante comum e cabe problematizarmos a nomeação dos sofrimentos em parâmetros de normalidade e doença.

Pretendemos, em última análise, sustentar a argumentação de que o aluno de psicologia, ao entrar em contato com a noção de diagnóstico em psicanálise e sua ética, pode ter ferramentas cruciais para problematizar de forma positiva seu trabalho de psicodiagnóstico e adquirir uma postura que o salvaguarde de um mau uso de tal instrumento.

\section{Psicodiagnóstico: normal versus patológico}

De maneira simples, para dizermos o que é anormal, temos que ter um ideal de normalidade, determinado a partir de padrões de comportamentos, pensamentos, estados mentais e condutas observáveis, que podem ser medidos, testados e catalogados, de forma que indique o que é um estado de saúde e de doença mental. Diferentes autores vão atribuir a cada segmento o que entendem como norma; portanto uma conduta humana "saudável" geralmente é avaliada de acordo com parâmetros e dogmas pré-estabelecidos. (DALGALARRONDO, 2008)

Georges Canguilhem (2009) vai se referir a patologia como uma variação normativa da vida, relacionando-se a vida e não a saúde do indivíduo. Com sua tese, promove um corte epistemológico e estabelece o rompimento de uma norma para que se afirme a existência de saúde ou doença, transformando apenas esses conceitos em um tipo de ideal vago e que nunca será alcançado, principalmente quando o sujeito é composto por suas subjetividades e características únicas em sua integralidade. O que é possível perceber em cada cultura, ou época, irá ter a sua perspectiva com o processo saúde/doença. O autor afirma que "não há nada na ciência que antes não tenha aparecido na consciência e que especialmente no caso que nos interessa, é o ponto de vista do doente que, no fundo, é verdadeiro". (CANGUILHEM, 2009, p. 68) Sendo assim o saber sobre o diagnóstico não pode estar dissociado da realidade do indivíduo.

Especificamente falando, o psicodiagnóstico deriva da junção entre a psicologia clínica e a tradição médica. A três autores é atribuída a paternidade do psicodiagnóstico, que iniciaram os seus estudos por volta do final século XIX: Galton, Cattell e Binet, que tiveram trabalhos que marcaram época e até hoje os seus nomes são referências no campo da psicologia. Galton trouxe contribuições com o estudo das diferenças individuais, Cattel, por sua vez, os testes mentais e Binet com a utilização de exames psicológicos. (FERNÁNDEZ-BALLESTEROS, 1986 apud CUNHA, 2003) Com o passar do tempo e estudos na área, autores mais contemporâneos atribuíram uma nova visão ao termo, passando assim a ter um olhar mais clínico, que entende o indivíduo como ser subjetivo. Seu objetivo passa a ser identificar no paciente o seu modo de funcionamento psicológico, contribuindo para uma nova visão de avaliação psicológica, observando sempre a importância da subjetividade e o rapport estabelecido entre terapeuta e paciente. (RIGONI e SÁ, 2016) É importante ressaltar que a avaliação psicológica pode ser realizada por profissionais de qualquer área da psicologia, mas somente o psicólogo clínico pode realizar o psicodiagnóstico.

Psicodiagnóstico é um processo científico, limitado no tempo, que utiliza técnicas e testes psicológicos (input), em nível individual ou não, seja para entender problemas à luz de pressupostos teóricos, identificar e avaliar aspectos específicos, seja para classificar o caso e prever seu curso possível, comunicando os resultados (output), na base dos quais são propostas soluções, se for o caso.(Cunha, 2003 p.26)

A literatura atual especializada ensina como procedimento princípios teóricos, métodos e técnicas de investigação como: entrevista, observação, testes psicológicos e técnicas projetivas, entrevista devolutiva e a elaboração de laudos, pareceres, entre outros. A escolha das estratégias e dos instrumentos que serão utilizados depende do referencial teórico, objetivo e finalidade da avaliação. É importante salientar que o psicodiagnóstico é um processo assentado em princípios científicos e, diferente da psicoterapia que pode se perpetuar por anos, o psicodiagnóstico apresenta um tempo determinado de atuação do psicólogo clínico. (CUNHA, 2003)

No psicodiagnóstico há um levantamento de hipóteses, que o caracterizam assim como um processo cientifico, e será a partir dos dados iniciais que se poderá estabelecer um plano de avaliação. Esse plano terá como base as perguntas e hipóteses iniciais, que irão nortear o psicólogo de quais instrumentos ele lançará mão e também quando e como utilizá-los, vinculados sempre com a história clínica e pessoal do sujeito e tendo como base as hipóteses iniciais e orientadas pelos objetivos do psicodiagnóstico. (CUNHA, 2003)

Ainda de acordo com Cunha (2003), as etapas do diagnóstico em psicodiagnóstico, resumidamente, 
apresentam-se da seguinte forma: no primeiro momento há um levantamento de perguntas acerca do encaminhamento ou motivo da consulta e a definição das hipóteses iniciais e os objetivos do exame; depois o delineamento e a delimitação de quais instrumentos serão utilizados, dando início a um levantamento qualitativo e quantitativo dos dados, havendo a integração dos dados e informações colhidas durante as sessões, tendo como ponto de referência os três primeiros itens anteriores, chegando, assim, a conclusão do processo, comunicando os resultados, orientações e encerramento do trabalho.

Quanto a atuação em psicodiagnóstico, se conjectura um preparo técnico e pessoal que requer uma qualificação e conhecimento de diversos saberes da psicologia e áreas afins, tendo sua formação base na graduação, mas que configura a cada especialista o cuidado de estar em constante atualização profissional quanto aos instrumentos e processos de avaliação. Além disso, é importante ressaltar que o psicólogo realize acompanhamento psicológico, investindo assim em seu desenvolvimento pessoal. Todas essas atribuições irão contribuir para que o psicólogo tenha melhores condições de analisar as demandas e definir os objetivos. Além da formação, da técnica e dos instrumentos utilizados, é importante que o psicólogo tenha sensibilidade clínica e uma postura ética no trato profissional. (HUTZ et al., 2016)

De praxe, o pedido para o psicodiagnóstico geralmente ocorre em função do aparecimento de algum comportamento considerado desviante, tanto no que diz respeito ao desenvolvimento cognitivo quanto ao comportamento no desempenho de atividades sociais. Usualmente, é utilizado como instrumento de classificação e diagnóstico do que seria considerado "desviante" o Manual Diagnóstico e Estatístico de Transtornos Mentais (DSM), que está em sua quinta edição, publicado pela Associação Americana de Psiquiatria (APA).

A Organização Mundial de Saúde (OMS) respalda as diretrizes do DSM e, de acordo como a mesma, saúde é conceituada como "um estado de completo bemestar físico, mental e social, e não consiste apenas na ausência de doença ou de enfermidade" (OMS, 1946, p. 1). Mas o que seria esse completo bem-estar? E o que haveria além da ausência de doença? Partindo dessa visão, no campo do sofrimento psíquico, não podemos desconsiderar o que Jerusalinsky e Fendrik apontam:

O invisível aos olhos, mas que habita na língua do DSM, é o consenso sobre a "ordem" que a sociedade espera dos filhos das famílias "normais": que sejam bons, carinhosos, tranquilos, adaptados, que aprendam bem "suas" lições, que comam e durmam bem e que, chegando o momento, estejam dispostos a defender até a morte, na guerra ou na paz, os valores do sistema. [...] A norma, a ordem, a média não explícitos é a (classe) média, "modelo", cujos filhos não devem ser "diferentes" dos pais, moldados pelo american-way-of-life. (JERUSALINSKY; FENDRIK,
2011, p. 34 apud RESENDE, PONTES, CALAZANS 2015)

Ao realizar uma avaliação psicológica afim de estabelecer um diagnóstico é importante cautela e serenidade. Quando bem conduzido, o diagnóstico pode contribuir para o indivíduo, dando-lhe uma dimensão do que é a sua doença, com um prognóstico e tratamento para a mesma. Mas há sério risco de se tornar um rótulo, causando prejuízos para a pessoa, enquadrando-o, reduzindo-o a um conjunto de sintomatologias e a uma nosologia. O sujeito se torna, então, apenas um objeto que possuirá um diagnóstico e intervenção.

As formas escolhidas para o enfrentamento desse
paradoxo podem ser classificadas em um continuum
que, num extremo, consiste em uma completa submissão
aos sistemas classificatórios, com a definição de tabelas
que relacionam entidades nosológicas ("doenças")
que "acometem" o sujeito com entidades terapêticas
("protocolos de tratamento") a que o sujeito portador da
"doença" deve ser "submetido", sob pena de se cometer
um "erro médico"." (BALIEIRO JR., 2005, p. 221)

Quandoéapenas utilizado osistemaclassificatório, deixamos de lado a singularidade do sujeito. De maneira mais radical, o que se percebe é que o sujeito desaparece, e o que fica é um número de pessoas que se enquadram na listagem de transtornos que o DSM-V (APA, 2014) e o CID 10 (OMS, 1993) disponibilizam, que mais se apresenta como um catálogo de doenças mentais, no qual se escolhe quais transtornos se encaixam mais ao discurso do paciente. Visto esse sistema, onde está a sua subjetividade? E a sua historicidade? A sua cultura? A sua crença? Essas indagações são deixadas de lado e incorre-se no erro de apenas dar escuta aos sintomas.

Surge, aqui, um segundo perigo a que esse plano de fratura submete a atividade psicodiagnóstica: o risco permanente de que, num extremo, seja apagada a integridade funcional da entidade pessoal ("sujeito") do "paciente" (ou seja, a sua "subjetividade") em nome de sua "classificação" em uma tabela de "doenças", ou, no extremo oposto, que sua "subjetividade" seja erigida em barreira, levando a que uma situação claramente solucionável através do uso de algum protocolo pré-definido seja submetida a tratamentos ineficazes.” (BALIEIRO JR, 2005, p. 221)

Éimportante ainda ressaltarque, além das questões de rotulação do sujeito, a avaliação psicológica tem padecido de um demérito, devido aos testes psicológicos utilizados não se adequarem a realidade brasileira. Segundo Weschsler (apud NORONHA, 2002), temos como problematizadores: as cópias deliberadas dos testes; não utilizar teste adequados ao proposto inicial; não estarem atualizados quanto às modificações da área; avaliações incorretas; não utilizar o material seguindo ao critério do teste; aplicação de teste por profissionais de outras áreas; não levar em consideração a cultura (país e região) em que a pessoa está inserida; 
e fazer interpretações "pessoais" para o resultado do teste. Autores como Almeida, Prieto, Muñiz e Bartram (1998) ressaltam também a falta de formação específica determinando assim uma conduta comum.

Pode-se entender que para os autores citados, os problemas encontrados na avaliação psicológica, e em especial nos testes psicológicos, referem-se prioritariamente à formação do profissional que utiliza os instrumentos, às deficiências nos próprios instrumentos, assim como à falta de pesquisas que promovam satisfatoriamente o desenvolvimento da área. Por trás deste cenário em que predominam controvérsias e polêmicas, existem duas preocupações básicas: como a avaliação tem sido entendida e utilizada pela comunidade profissional e como ela tem sido proposta e ensinada nos cursos preparatórios." (NORONHA, 2002, p. 137)

Esta é uma ampla discussão, mas gostaríamos de voltar novamente o olhar ao perigo do psicodiagnóstico ser reducionista quanto ao sujeito, desconsiderando sua singularidade. O alicerce do DSM foi construído a partir de uma orientação biopolítica, que "[...] prescreve a fixação de categorias identitárias, monossintomáticas, visando colocar em circulação novos modos de captura da experiência subjetiva e a redução das margens de não conformidade às regras sociais" (LIMA et al., 2010, p. 58). Nossa vivência em outro campo de estágio, o da Terapia Psicanalítica, nos habilita afirmar que para a psicanálise, o que vai ser posto em movimento pelo sujeito é o que está por trás do sintoma, aquele fenômeno que para o psicodiagnóstico é a psicopatologia, que se limita a trabalhar apenas a taxonomia das patologias e não o sofrimento psíquico do sujeito, assumindo assim as diferenças técnico-científicas destes saberes e das suas particularidades em diagnóstico. Nessa conjuntura, a psicanálise traz uma fundamental relevância que será concedida à experiência do real e suas modalidades clínicas.

\section{O diagnóstico em Psicanálise: 0 avesso do Psicodiagnóstico}

Em sua obra "Estruturas e clínica psicanalítica", Joël Dor (1991) afirma que o diagnóstico é um ação de natureza médica, que possui dois objetivos, a saber: a observação, que determinaria a natureza de uma enfermidade a partir de uma semiologia, desenvolvendo uma etiologia; e a classificação, que colocaria tal enfermidade como um estado patológico no quadro de uma nosografia, para que se produza um diagnóstico diferencial. A utilidade desse processo se justificaria ao facilitar a escolha do tratamento mais apropriado.

A psiquiatria clássica ergueu uma disciplina do diagnóstico sobre o modelo de investigação e tratamento da doença orgânica, tal como fora prescrito pela medicina [...]. Tal disciplina obedecia ao seguinte ordenamento: em primeiro lugar, tratava-se de observar e descrever exaustivamente as características fenomenológicas das doenças (índices e sinais); em segundo lugar, de organizar essa fenomenologia vasta em classes de sintomas; em terceiro, de localizar, por meio da técnica do exame, um correlato anátomofisiológico para tais sintomas (uma lesão orgânica) e em quarto lugar de determinar um agente patológico externo como causa da lesão. (LIMA et al., 2010, p. 52)

Freud (1913/1996) ensina que, para a condução do tratamento sem interrupções, inicialmente a análise se dá em um tempo em que ele vai chamar de tratamento de ensaio, importante tempo por vários motivos, dentre eles, para se estabelecer o laço transferencial entre psicanalista e paciente. Antônio Quinet (2009) nos esclarece que esse tempo de ensaio analítico terá como função a instauração do diagnóstico diferencial, e nos lembra a importante assertiva lacaniana: "[...] não há entrada em análise sem as entrevistas preliminares". (LACAN apud QUINET, 2009, p. 14) O diagnóstico em psicanálise ocorre, portanto, somente a partir de um tempo de tratamento, através do vínculo transferencial que o paciente estabelece com o analista. Entende-se, acima de tudo, que o paciente é atravessado por sua subjetividade e a sua realidade psíquica será determinante como a forma que ele decodifica o mundo.

A psicanálise "dá à cura um estatuto mais 'pessoal', porque ela procede, de saída, e no decorrer de seu exercício, a uma demarcação clínica diferente." (PORGE, 2009, p. 9) Não irá trabalhar com o sujeito de acordo com a sua dita patologia e sim a partir de seu sofrimento psíquico, nomeado pelo paciente como sintoma. O diagnóstico psicanalítico é efeito do manejo da análise e não funciona como forma de patologização, porque o que vale é o que está por trás do sintoma que o analisando se queixa. Ela vai na contramão dos saberes que consideram as diferentes formas de diagnósticos como "ponto final', que determinam o que é normal e anormal, saúde e doença a fim de normatizar sujeitos complexos e multifacetados como são os seres humanos.

\footnotetext{
Freud e depois Lacan sublinharam que a cura vinha como lucro. O que quer dizer que ela pode dar-se, mas por outras vias que não aquelas que visariam diretamente a uma melhora sintomática: por vias que implicam desvios, que abordam com prudência a cura - uma vez quer ela não é, forçosamente, o que o sujeito demanda [...] (PORGE, 2009, p. 9)
}

A clínica psicanalítica teve seu começo com a escuta dos sintomas neuróticos. No entanto, antagônico ao uso da escuta pelos médicos de seu tempo, Freud nãofugiu da proeminência de uma Outra cena, presente no testemunho de seus doentes. Foi a partir da escuta dos sintomas, mas de uma atitude de investigação e não de mestria higienista, que o pai da psicanálise teve acesso às instabilidades do sujeito frente ao traumático da sexualidade e ao Inconsciente. "Um dia descobriuse que os sintomas patológicos de determinados 
pacientes neuróticos têm um sentido. Nessa descoberta fundamentou-se o método psicanalítico de tratamento" (FREUD, 1916/1996, p. 89). Fundou uma prática ética fundamentada na indagação dos impulsos pulsionais, das formações do Inconsciente e do traumático da sexualidade.

Freud propõe uma nova visão do sujeito ao fundar o inconsciente e articular seus movimentos à satisfação da energia pulsional, que se apresenta como a manifestação do inconsciente em ação: o sintoma, então, é o caminho econômico que o inconsciente encontrou para dar conta de uma certa tensão. A psicanálise vai além das categorizações sintomáticas típicas de sua época e se pergunta o porquê do sintoma? Qual é a sua causa? A clínica psicanalista busca dar voz ao sujeito e não os enquadrar em uma patologia, procurando raízes psíquica de tais sofrimentos, de forma não reducionista do sujeito a sua sintomatologia. "Na clínica analítica, o ato diagnóstico é necessariamente, de partida, um ato deliberadamente posto em suspenso e relegado a um devir. (DOR, 1991, p. 15)

É importante ressaltar que o sintoma é efeito da inserção do sujeito na ordem da linguagem e que uma investigação diagnóstica precisa ir além das queixas sintomáticas. Para Freud o sintoma tem um sentido para o sujeito e se apresenta de acordo com as suas experiências: "Não apenas o sentido dos sintomas é, com regularidade, inconsciente, mas também existe uma relação inseparável entre este fato de os sintomas serem inconscientes e possibilidade de eles existirem". (FREUD, 1916/1996, p. 28)

Uma vez que não é possível um aspecto absoluto do sujeito lido pelo significante, é o sintoma em sua forma mais inconfundível e única para tal, que o consente a se haver com seu gozo. "É porque a representação significante só pode liberar um sujeito dividido, é porque jamais se realiza sem produzir uma perda de gozo, que o mais-gozar, aparelhado pelo sintoma, vem funcionar como solução." (VENTURINI, 2007, p.179) Dessa maneira, o sintoma comparece como um recurso que se edifica para conformar o inconciliável, ou seja, as duas reações conflitantes de um sujeito ao trauma. (BESSET, 2006)

A cada sessão, no ato de convidar a falar, o psicanalista renova a aposta freudiana na radicalidade que representa a experiência do inconsciente para o sujeito. É do pathos, do espanto do analisando frente sua condição de falasser, que a teoria psicanalítica retira os elementos fundamentais para sua eterna construção teórica. O que nos faz pensar: de todos os sintomas possíveis, por que o sujeito faz esse? Qual é o gozo por trás do sintoma? Dessa forma, o sintoma passa de um código de resposta para uma questão para o sujeito. $\mathrm{O}$ analisante se dirige ao analista, como alguém que possui um suposto saber sobre o seu sintoma, movimento correspondente ao que Lacan chama de discurso da histérica, que se configura no sujeito barrado que se direciona ao mestre (S1) para que o mestre devolva para ele um suposto saber (S2). Esta manobra está fadada ao fracasso, por conta de não ser possível resolver a verdade do gozo. (LACAN, 1969-70/1992)

Opostamente às terapias psicológicas que também tratam pela linguagem e pela escuta, a psicanálise trata, acima de qualquer elemento, do "traumatismo da linguagem pela escrita formal do sintoma. Ela não identifica, ela descompleta" (BROUSSE, 2003, p. 23). A psicanálise é apreendida, também, como um discurso, ou melhor, como aquilo que produz liame social. Mas não é qualquer discurso porque, subversivamente, não se pretende como tal. O discurso do psicanalista é aquele que aloca o saber no sítio da verdade e isso determina consequências muito características, porque a verdade, como uma certeza total e maciça, não tem lugar na psicanálise: "Tal uso [...] é particularmente desprovido de esperança. E é justamente isso que ele tem de mais sadio", afirma Lacan (1969-70/1992, p. 57)

Nos ensinamentos psicanalíticos, o sintoma pode ser entendido por algumas lentes. Uma delas é a ideia de sintoma como mensageiro de um código cifrado do Inconsciente. Essa noção tem seu desenvolvimento nos textos freudianos anteriores a 1920. Outra lente possível é a pulsional, que dirige para além do princípio do prazer, unida a repetição, ao gozo e à pulsão de morte, noção ampliada após 1920. Numa outra configuração, o sintoma, como formação do inconsciente, está unido a uma satisfação de desejo. Contudo, esta satisfação é paradoxal: da mesma maneira que garante a homeostase do aparelho psíquico, é determinante para o sofrimento porque determina um franqueamento da satisfação, porque funciona como uma formação de compromisso entre duas forças: a libido insatisfeita, devido ao mecanismo do recalque, e a força repressora que a mantém dentro dos limites impostos pela cultura. "[...] pelo caminho indireto, via inconsciente e antigas fixações, a libido finalmente consegue achar uma saída até uma satisfação real - embora seja uma satisfação extremamente restrita e que mal se reconhece como tal." (FREUD, 1916-17/1996, p. 421-22)

É no aprendizado da clínica psicanalítica que se regula o real pelo impossível de se dizer. Esse campo tem como bússola trazer o que é da ordem do sofrimento para o regime da palavra. Mas a experiência psicanalítica está sempre assinalando para a direção do ab-senso (ab-sens), da ausência. Ou seja, ao escolher eticamente depositar como agente do seu discurso o que é indizível, a psicanálise se ampara no real, ponto de escapada da referência simbólica, no misterioso que extrapola a possibilidade de apreensão. O real, apreendido como aquilo que é impossível de simbolizar, apresentar-se na interrogação nuclear da psicanálise, a saber, a questão da diferença sexual. (LACAN, [1972] 2003)

A psicanálise não visa restabelecer significações, 
mas seu dizer. Mostrar o que está além das significações e alcançar um efeito de subversão. É preciso que esses princípios operem na escuta e no manejo da clínica para que possa se garantir que o que se faz é psicanálise e não uma ortopedia do sujeito. Levar em conta a lógica do não-todo no manejo clínico é obter o efeito inverso da normatização diagnóstica: é a produção do novo que, distanciado da repetição de significações, causa a separação justo onde se localiza a fronteira entre o sujeito e o objeto. Uma estratégia baseada na avidez de classificar e formatar, por outro lado, visa restaurar a base da fantasia, abalada por alguma contingência da vida. No lugar das significações abaladas, colocam-se outras para restaurar e colmatar uma falha. (SOLER, 1995) E assim, o discurso cria um deslizar de ditos, que segue incessante até que se produza um conjunto de significações que possa abrandar a angústia causada pela vacilação da fantasia.

É necessário ter em mente que qualquer dispositivo, para que seja nomeado psicanalítico, deve operar sem a mediação de um saber prévio e "operar a partir de um furo no saber, o que implica na sustentação de um real, único capaz de dar lugar ao inconsciente." (ELIA, 2005, p. 117) Cabe então, refletir sobre uma prática "[...] preocupada acima de tudo em causar a mais pura diferença a partir da não elisão do real e do acolhimento do que é próprio do ser falante e sua condição desamparada frente à linguagem, ao desejo e ao gozo. (SAMICO, 2018, p. 173) Para, a partir do contingencial, mostrar o que não muda da ordem do necessário e que se fixará como sinthoma. (Samico, 2016)

A intervenção psicanalítica, com sua escuta característica, dirige para um domínio mais adiante do sintoma e da demanda, porque aposta na articulação entre sujeito, desejo e palavra em um espaço privado: o setting analítico. É desse lugar ético que é presumível improvisar a altercação entre o saber e o rochedo da castração. É a extraordinariedade da singularidade que a análise apoia, porque a psicanálise determina o aprendizado da diferença no significado de consentir que sujeito e objeto possam ser entendidos a partir de sua não representabilidade, culminantes na categoria da Coisa. Seu desígnio é um poder desejar na divisão própria que funda o sujeito, amparado na castração, e poder passar de objeto do desejo do outro a sujeito do desejo na travessia da fantasia. A ocupação do analista é antagônica ao treinamento das pulsões para melhor ajuste do sujeito às demandas dos valores culturais. Daí, alcança-se que a escuta que necessitamos sustentar precisaria ter o pacto de ir no oposto da virtude cuja promessa é a felicidade, e direcionar-se ao desejo inconsciente e seu papel no conflito psíquico.

\section{Considerações Finais}

Na experiência do estágio em Psicodiaginóstico, entramos em contato com encaminhamentos que vem das mais variadas instâncias. No entanto, as escolas são as que mais encaminham e solicitam pareceres, para que possam obter uma orientação e compreensão de crianças e jovens que porventura tenham "problemas" de cunho comportamental, cognitivo e/ou afetivo. A avaliação psicológica toma-se um importante e, acima de tudo, perigoso instrumento porque há a exigência de que, na avaliação psicodiagnóstica, deve-se definir qual é a tomada de decisão mais indicada para a saúde mental da criança ou adolescente em avaliação. A psicanálise, por sua vez, possibilita reintroduzir no cerne do discurso humano a dimensão da verdade como não-toda a partir da fala, e a dimensão do saber naquilo que se articula ao sujeito barrado, para sustentar a insistência na construção de um lugar de enunciação possível para os sujeitos que buscam uma resposta para seus sintomas. Contrariamente a Aristóteles, a verdade que é buscada na experiência analítica não é a de uma lei superior. Procura-se uma verdade no "[...] ponto de sonegação de nosso sujeito. É uma verdade particular" (LACAN, 1959- 60/1988, p. 35).

Quando o aluno entra em contato com a psicanálise, percebe sua exigência ética que demandaria um posicionamento de escuta do sujeito, pura e simplesmente. A ética da psicanálise está localizada na via do desejo, por isso distante da preocupação em adaptar o homem aos ideais sociais. Neste contexto, o encaminhamento ao psicodiagnóstico deve ser percebido, antes e acima de tudo, como pertinente a um sujeito que é responsável e competente na construção de sua própria vida e de sua própria história.

\section{Referências Bibliográficas}

ALMEIDA, Leandro S. et al. O uso dos testes em Portugal, Espanha e Países Ibero-Americanos. Psychologica, Coimbra. V. 20, n. 1. P. 27-40, 1998.

AMERICAN PSYCHIATRIC ASSOCIATION (APA). Manual Diagnóstico e Estatístico de Transtornos Mentais (DSM-V). 5. ed. Porto Alegre: Artmed, 2014.

BALIEIRO JUNIOR, A. P. Psicodiagnóstico e psicoterapia dimensões e paradoxos. Psicol. cienc. prof., Brasília, v. 25, n. 2, p. 212-227, jun 2005. Disponível em <http://pepsic.bvsalud.org/scielo.php?script=sci arttext\&pid $=$ S1414-98932005000200005\&lng=pt\&nrm=iso $>$. Acessos em 10 mar. 2019.

BESSET, V. L. et al. Trauma e sintoma: da generalização à singularidade. Revista Mal Estar e Subjetividade, Fortaleza, v. 6, n. 2, p. 311-31, 2006.

BROUSSE, M. . O inconsciente é a política. São Paulo: Escola Brasileira de Psicanálise, 2003. p. 13-32.

CANGUILHEM, G. $(1943,1995)$ O normal e o patológico. Rio de Janeiro: Forense Universitária. 2009 
DOR, J. Estruturas e clínica psicanalítica. Rio de Janeiro: Taurus-Timbre, 1991.

ELIA, L. O conceito de sujeito. Rio de Janeiro: Jorge Zahar, 2004.

FREUD, S. (1913) Sobre o Início do Tratamento (Novas recomendações sobre a técnica da psicanálise I). Edição Standard Brasileira das Obras Completas de Sigmund Freud, vol. XII. Rio de Janeiro: Imago, 1996.

(1916 [1916-1917]) Conferências introdutórias sobre psicanálise, parte III, Psicanálise e Psiquiatria: conferência XVI. Edição Standard Brasileira das Obras Completas de Sigmund Freud, vol. XVI. Rio de Janeiro: Imago, 1996.

(1917 [1916-1917]) Conferências introdutórias sobre psicanálise, parte III, O Sentido dos Sintomas.: conferência XVII. Edição Standard Brasileira das Obras Completas de Sigmund Freud, vol. XVI. Rio de Janeiro: Imago, 1996.

HUTZ, C. S. et al. (Orgs.). Psicodiagnóstico. Porto Alegre: Artmed. 2016

LACAN, J. O seminário, livro 7: a ética da psicanálise. Rio de Janeiro: Jorge Zahar, 1988.

. O seminário, livro 17: o avesso da psicanálise. Rio de Janeiro: Jorge Zahar, 1992.

. Outros escritos. Rio de Janeiro: Jorge Zahar, 2003. p. 448-497.

LIMA, C.H. etal.Diagnóstico diferenciale direção do tratamentonaatualidade: do DSM-IV à psicanálise. Arq. bras. psicol., Rio de Janeiro, v. 62, n. 1, p. 4961, abr. 2010. Disponível em http://pepsic.bvsalud.org/scielo.php?script=sci arttext\&pid=S1809-52672010000100006\&lng=pt\&nrm=iso. Acesso em $1 \overline{3}$ ago. 2019

MILLER, J. Lacan elucidado. Rio de Janeiro: Jorge Zahar, 1997.

NORONHA, A. P. P.. Os problemas mais graves e mais frequentes no uso dos testes psicológicos. Psicol. Reflexo. Crit., Porto Alegre, v. 15, n. 1, p. 135-142, 2002. Disponível em http://www.scielo.br/scielo.php?script=sci arttext\&pid=S0102-79722002000100015\&lng=en\&nrm=iso. Acesso em $1 \overline{4}$ de mar. de 2019.

ORGANIZAÇÃO MUNDIAL DE SAÚDE (OMS). Classificação de Transtornos Mentais e do Comportamento da CID-10: descrições clínicas e diretrizes diagnósticas. Porto Alegre: Artmed, 1993.

ORGANIZAÇÃO MUNDIAL DE SAÚDE (OMS). 1946. Constituição. Disponível em <http://www.onuportugal.pt/"oms.doc>. Acesso em 11 de junho de 2019.

PORGE, Erik. Transmitir a clínica psicanalítica. Campinas: Unicamp, 2009. QUINET, A. As 4+1 Condições de Análise. 12. ed. Rio de Janeiro: Jorge Zahar, 2009.

RESENDE, M. S.; PONTES, S.; CALAZANS, R. O DSM-5 e suas implicações no processo de medicalização da existência. Psicol. rev., Belo Horizonte , v. 21, n. 3, p. 534-546, set. 2015 . Disponível em http://pepsic.bvsalud.org/scielo.php?script $=$ sci arttext\&pid=S1677$11682015000300008 \&$ lng=pt\&nrm=iso. acessos em 19 jul. 2019. http:// dx.doi.org/DOI-10.5752/P.1678-9523.2015v21n3p534.

RIGONI, M. S.; SÁ, S. D. O processo psicodiagnóstico. In HUTZ, C. S. et al. (Orgs.), Psicodiagnóstico. Porto Alegre: Artmed, 2016. p. 27-34.

SAMICO, F. C. A escuta clínica de policiais militares: violência, trauma e sintoma. Mosaico - Revista Multidisciplinar de Humanidades, Vassouras, RJ, v. 7, n. 2, p. 10-14, jul./dez. 2016. Disponível em: <http://editora. universidadedevassouras.edu.br/index.php/RM/article/viewFile/465/pdf $>$

. A supervisão psicanalítica na universidade e a instituição polícia militar: relato de uma experiência. 2018. Tese (Doutorado em Psicanálise) Programa de Pós-Graduação em Psicanálise, Universidade do Estado do Rio de Janeiro, Rio de Janeiro, 2018

SOLER, C. Interpretação: as respostas do analista. Opção Lacaniana, São Paulo, n. 13, p. 20-38, ago. 1995.

VENTURINI, S. O sintoma e os impasses na análise.Psyche, São Paulo, v. 11 , n. 20 , p. $165-182$, jun. 2007 